\title{
Development of Spontaneous Hygromycin B Resistance in Monilinia fructicola and Its Impact on Growth Rate, Morphology, Susceptibility to Demethylation Inhibitor Fungicides, and Sporulation
}

\author{
Qun Dai, Zhihuan Sun, and Guido Schnabel
}

Department of Entomology, Soils, and Plant Sciences, 218 Long Hall, Clemson University, Clemson, SC 29634. Current address of Q. Dai and Z. Sun: Department of Medicine, University of Alabama, Birmingham 35294. Accepted for publication 30 April 2003.

\begin{abstract}
Dai, Q., Sun, Z., and Schnabel, G. 2003. Development of spontaneous hygromycin B resistance in Monilinia fructicola and its impact on growth rate, morphology, susceptibility to demethylation inhibitor fungicides, and sporulation. Phytopathology 93:1354-1359.

Agrobacterium tumefaciens-mediated transformation with plasmids carrying the hygromycin B resistance gene $h p h$ frequently is being used for inserting genes into fungal spores and mycelial cells and for conducting insertional mutagenesis to identify genes connected to a particular phenotype. In this article, we report that stable hygromycin B resistance can develop spontaneously in germinating conidia from Monilinia fructi-

agar, were 2.4- to 3.1-fold more sensitive to demethylation inhibitor fungicides, lacked melanization, and did not produce spores. The mode of action of hygromycin B resistance in the mutants seemed to be different from the $h p h$ transgene-mediated hygromycin B resistance based on different phenotypic characters. The ability of $M$. fructicola and possibly other fungi to spontaneously develop hygromycin B resistance associated with an altered phenotype may interfere with the selection of true transformants if hygromycin B is used as selective agent. This is particularly confounding if the $h p h$ gene is used as selectable marker in insertional mutagenesis experiments conducted for the identification of genes involved in melanization, sporulation, or fungicide resistance.
\end{abstract} cola and that the mutants exhibit altered phenotypes. One spontaneously developing hygromycin B-resistant colony developed per $2.5 \times 10^{5}$ germinating conidia. Mutants grew significantly slower on potato dextrose
Additional keywords: brown rot, stone fruit.
Monilinia fructicola (G. Wint.) Honey is the causal agent of brown rot, one of the most destructive diseases of stone fruit worldwide $(1,2,13,14)$. The fungus causes blossom and twig blight and infects green and mature fruit. A few fruit infections may lead to the production of millions of spores capable of causing a disease epidemic, particularly during moist field conditions in the last 3 weeks before harvest. In addition, it is not uncommon that half of seemingly healthy fruit will deteriorate due to brown rot in the first week after harvest under cool and moist storage conditions (23).

Control of the disease has been dependent largely on demethylation inhibitor (DMI) fungicides, which exhibit low toxicity profiles and high fungicidal efficacy at low application rates. However, reduced sensitivity in $M$. fructicola strains to DMI fungicides has been documented recently in an experimental orchard in South Carolina (28), a development of great concern for commercial stone fruit growers.

Despite the worldwide importance of brown rot, little is known about the molecular basis of important processes such as sporulation, pathogenicity, or fungicide resistance in $M$. fructicola. A transformation system for $M$. fructicola is needed to study the molecular basis of these processes. Transformation of M. fructicola is complicated by the multinucleate state of macroconidia and hyphal cells $(10-12,27)$, which would result in the formation of heterokaryons comprising both transformed and untransformed nuclei. Repeated hyphal-tip transfers of macroconidial transformants to enrich the transformed nuclei or passage through a sexual cycle

Corresponding author: G. Schnabel; E-mail address: schnabe@clemson.edu

Publication no. P-2003-0825-01R

(C) 2003 The American Phytopathological Society or production of uninucleate microconidia would be options to purify homokaryotic transformants $(15,22)$.

Genetic transformation of cells, including fungal cells, requires the selection of transformants using antibiotics. Hygromycin B is currently the most commonly used selection agent in genetic transformation of fungi $(7,8)$ due to its broad-spectrum activity. However, some fungi are naturally resistant to hygromycin B (4). In this study, we show that germinating $M$. fructicola conidia may develop stable, spontaneous resistance to hygromycin B and that the hygromycin B-resistant mutants are impacted in growth rate, sensitivity to DMI fungicides, melanization, and sporulation. It is concluded that hygromycin B may not be a suitable selective agent in $M$. fructicola transformation experiments, especially if genes involved in fungicide resistance, melanization, and sporulation are sought.

\section{MATERIALS AND METHODS}

Origin and single spore isolation of $M$. fructicola isolates DL25W, DL15W, and SY3. Peach fruit infected with $M$. fructicola were collected in the summer of 2000 from an abandoned peach orchard (DL) in Anderson County, SC and from a commercial orchard (SY) in Edgefield County, SC. The counties are $150 \mathrm{~km}$ apart. Conidia were scraped off the fruit with a sterile toothpick and transferred to $1 \mathrm{ml}$ of water. After vortexing, $50 \mu \mathrm{l}$ of the conidial suspension was distributed evenly onto water agar amended with streptomycin sulfate at $100 \mu \mathrm{g} / \mathrm{ml}$. Hyphal tips from germinating conidia were transferred aseptically to potato dextrose agar (PDA; Difco Laboratories, Sparks, MD). Two single spore isolates from different fruit of orchard DL (DL25W and DL15W) and one single spore isolate from orchard SY (SY3) were selected at random for further experiments. 
Production of conidia and nontransformed, hygromycin Bresistant colonies from $M$. fructicola isolates DL25W, DL15W, and SY3. Commercially prepared peeled peach halves (peach halves in light syrup; Del Monte Foods, San Francisco) were placed in 400-ml beakers (one peach half per beaker), pit side facing down. Fruit surfaces were inoculated with agar plugs ( $5 \mathrm{~mm}$ in diameter; one plug per half fruit) obtained from the periphery of a 5-day-old colony cultivated on PDA. After 10 days of incubation at $25^{\circ} \mathrm{C}$, conidia were harvested from the peach surface and suspended in sterile water at a final concentration of $10^{6}$ conidia/ml.

Hygromycin B-resistant mutants were obtained following the protocol for transforming Fusarium oxysporum with $200 \mu \mathrm{M}$ acetosyringone (18) but without the addition of Agrobacterium tumefaciens. Briefly, $2 \mathrm{ml}$ of the $M$. fructicola conidial suspension was distributed evenly on a 90-mm-diameter filter paper (P8creped; Fisher, Pittsburgh, PA), then placed on solid induction medium (3) in petri dishes (18). After 2 days of incubation at $25^{\circ} \mathrm{C}$, the filters were transferred to PDA containing hygromycin $\mathrm{B}$ at $50 \mu \mathrm{g} / \mathrm{ml}$ (Sigma-Aldrich, St. Louis). After 6 to 8 days, colonies were transferred to fresh plates containing hygromycin B at $50 \mu \mathrm{g} / \mathrm{ml}$. Three hygromycin B-resistant colonies, designated 4-26, $5-18$, and 5-26, derived from isolate DL25W, were selected at random for further experiments and are referred to as DL25 mutants.

Transformation of DL25W with the hygromycin B resistance gene $\boldsymbol{h p h}$. Transformation of germinating conidia from DL25W was conducted via Agrobacterium tumefaciens (strain AGL-1)-mediated transformation following the protocol for transforming $F$. oxysporum with $200 \mu \mathrm{M}$ acetosyringone included in the induction medium (18). AGL-1 contained vector pBHt1 (18) with the hygromycin $\mathrm{B}$ resistance gene $h p h$ under the control of the trpC promoter from Aspergillus nidulans. Transformants were selected on PDA amended with hygromycin B at $50 \mu \mathrm{g} / \mathrm{ml}$. One transformant, DL25H, was selected at random for further experiments.

DNA isolation and polymerase chain reaction amplification of ribosomal DNA. DL25W, DL25H, and the DL25 mutants were cultured in $50 \mathrm{ml}$ of potato dextrose broth (PDB; Difco Laboratories) for 7 days at $25^{\circ} \mathrm{C}$ with continuous shaking at $150 \mathrm{rpm}$. Mycelial mats were collected on nylon mesh, frozen in liquid nitrogen, and ground into fine powder. The powder was added to extraction buffer $(50 \mathrm{mM}$ Tris- $\mathrm{HCl}, 50 \mathrm{mM}$ EDTA, $2 \%$ sodium dodecyl sulfate, $2 \%$ 2-mercaptoethanol, $\mathrm{pH} 8.0$ ) and incubated for $3 \mathrm{~h}$ at $65^{\circ} \mathrm{C}$. Following addition of one volume of phenol/chloroform (1:1; EM Science, Gibbstown, NJ) the sample was shaken at $100 \mathrm{rpm}$ at $25^{\circ} \mathrm{C}$ for $30 \mathrm{~min}$ and then centrifuged at $12,000 \times g$ for $10 \mathrm{~min}$. The upper aqueous phase was mixed with one volume of isopropanol and centrifuged at $12,000 \times g$ for $10 \mathrm{~min}$. The resultng pellet was dissolved in Tris-EDTA (TE) buffer, amended with RNase A at $100 \mu \mathrm{g} / \mathrm{ml}$, and kept at $37^{\circ} \mathrm{C}$ for $30 \mathrm{~min}$. Following a second phenol/chloroform extraction, the DNA was precipitated with $1 / 10$ volume of $3 \mathrm{M}$ sodium acetate ( $\mathrm{pH}$ 5.2) and 2 volumes of absolute ethyl alcohol. After centrifugation, the DNA pellet was dissolved in TE buffer. DNA concentrations were measured with a GeneQuant pro spectrophotometer (Biochrom Ltd., Cambridge, England). Primers internal transcribed spacer (ITS)1-F and ITS2 were used to amplify the ribosomal ITS1 region via polymerase chain reaction (PCR) (26). The amplified products were digested with the endonuclease MseI (New England Biolabs Inc., Beverly, MA) following a protocol described previously (24). Additionally, the ribosomal ITS1 and ITS2 of DL25W, the DL25 mutants, and DL25H were amplified and sequenced with ITS1-F and ITS4 (24).

Agrobacterium DNA for PCR amplification was obtained as follows. An Agrobacterium colony was transferred with a sterile probe to $50 \mu \mathrm{l}$ of TE buffer and incubated at $99.5^{\circ} \mathrm{C}$ for $5 \mathrm{~min}$, after which the mixture was centrifuged at 10,000 rpm for $1 \mathrm{~min}$. This mixture $(5 \mu \mathrm{l})$ was used as PCR template.
Analysis of DL25W, DL25 mutants, and the DL25H transformant. The presence or absence of the $h p h$ gene in DL25H, DL25W, and the DL25 mutants was determined by PCR using $h p h$-specific primers, hph-F (5'-TGT TTA TCG GCA CTT TGC ATC-3') and hph-R (5'-CAT CAT CGA AAT TGC CGT CA-3'). The primers were designed using the Saccharomyces Genome Database Web Primer design software. PCR reaction mixtures $(20 \mu \mathrm{l})$ contained $20 \mathrm{ng}$ of genomic DNA, $2 \mu \mathrm{M}$ each primer, $200 \mu \mathrm{M}$ each dNTP, 0.5 units of Taq (DNA polymerase; Invitrogen, Carlsbad, CA), $20 \mathrm{mM}$ Tris- $\mathrm{HCl}(\mathrm{pH} \mathrm{8.4)}, 50 \mathrm{mM} \mathrm{KCl}$, and $5 \mathrm{mM}$ $\mathrm{MgCl}_{2}$. Reactions were performed in an "icycler" thermal cycler (Bio-Rad Laboratories Inc., Hercules, CA) using the following PCR program: an initial denaturation step at $94^{\circ} \mathrm{C}$ for $2 \mathrm{~min} ; 30$ cycles of $94^{\circ} \mathrm{C}$ for $30 \mathrm{~s}, 60^{\circ} \mathrm{C}$ for $40 \mathrm{~s}$, and $72^{\circ} \mathrm{C}$ for $1 \mathrm{~min}$; and a final extension at $72^{\circ} \mathrm{C}$ for $7 \mathrm{~min}$. The presence or absence of Agrobacterium DNA in the DL25 mutants and DL25H was determined by PCR amplification of the Agrobacterium flagellar switch protein gene with primers 5'-CCG GCA AGC TGC TGA AAT-3' and 5'-CGT CTG AGC CGA GGA AAT GA-3' as described previously (25).

Mycelial growth on PDA and PDA amended with hygromycin or various DMI fungicides. Sensitivity of $M$. fructicola isolates and mutants to hygromycin B or DMI fungicides was determined as described previously (28). Basically, PDA was autoclaved and fungicides were incorporated after cooling the media to $60^{\circ} \mathrm{C}$. Medium $(30 \mathrm{ml})$ was placed in petri dishes $(15$ by $90 \mathrm{~mm})$. Three plugs $(5 \mathrm{~mm}$ in diameter) taken from the periphery of 5-day-old mycelium grown on PDA were placed equidistantly on the solidified medium. Cultures were incubated at $25^{\circ} \mathrm{C}$ in the dark, and colony diameters were measured after 3, 4, 5, and 6 days.

Hygromycin B was added to PDA at final concentrations of 0 , $10,30,50,300$, and $500 \mu \mathrm{g} / \mathrm{ml}$ to evaluate the sensitivity of isolates DL25W, DL13W, and SY3 and the DL25 mutants. Myclobutanil (Nova 40W; Rohm \& Haas, Philadelphia, PA) was added at final concentrations of $0,0.05,0.1,0.5,1.0,5.0$, and $10.0 \mu \mathrm{g} / \mathrm{ml}$; propiconazole (Orbit 3.6E; Syngenta Crop Protection, Greensboro, NC) and fenbuconazole (Indar 75WSP; Rohm \& Haas) both were added at final concentrations of $0,0.001,0.005,0.01,0.05$, 0.1 , and $0.5 \mu \mathrm{g} / \mathrm{ml}$. Effective concentration (50\%) values were calculated by regressing the relative growth (colony diameter on DMIamended medium divided by the diameter on unamended medium multiplied by 100) against the log of the fungicide concentration.

Mycelial growth and sporulation on peach halves. The experimental setup for assessing mycelial growth and sporulation on peach halves was identical to the protocol described above to obtain M. fructicola DL25W spores. Each isolate was grown on six peach halves and diameters of the mycelial colonies on peach surfaces were measured after $3,4,5$, and 6 days. The presence or absence of conidia was determined after 4, 10, and 21 days using an Olympus BX41 microscope (Opelco, Dulles, VA). Basically,

TABLE 1. Development and stability of hygromycin B resistance in germinating conidia of Monilinia fructicola isolate DL25W

\begin{tabular}{|c|c|c|c|}
\hline \multirow[b]{2}{*}{ Experiment no. } & \multicolumn{2}{|c|}{ Hygromycin B-resistant mutants (no.) ${ }^{\mathrm{y}}$} & \multirow{2}{*}{$\begin{array}{c}\text { Stability of } \\
\text { resistance }(\%)^{\mathrm{z}}\end{array}$} \\
\hline & Selection 1 & Selection 2 & \\
\hline 1 & 186 & 75 & 40.3 \\
\hline 2 & 25 & 8 & 32.0 \\
\hline 3 & 11 & 5 & 45.5 \\
\hline 4 & 23 & 9 & 39.1 \\
\hline 5 & 39 & 11 & 28.2 \\
\hline 6 & 12 & 6 & 50.0 \\
\hline
\end{tabular}

y A total of $2 \times 10^{6}$ conidia were plated on induction medium in the absence of Agrobacterium tumefaciens. After 2 days, germinating conidia were transferred to potato dextrose agar (PDA) amended with $50 \mu \mathrm{g}$ of hygromycin B per $\mathrm{ml}$ (selection 1). Developing colonies were subsequently transferred to PDA amended with $50 \mu \mathrm{g}$ of hygromycin B per ml (selection 2).

$\mathrm{z}$ The stability of resistance represents the percentage of colonies successfully transferred to fresh selective medium. 
mycelium was scraped off the peaches, suspended in $1 \mathrm{ml}$ of sterile water, and centrifuged for $1 \mathrm{~min}$ at 10,000 rpm, after which $900 \mathrm{ml}$ of the upper phase was discarded. The remaining $100-\mu \mathrm{l}$ mycelium suspension was vortexed vigorously and examined under the microscope.

Statistical analysis. Data analyses were performed with Sigma Stat software (Jandel Corporation, San Rafael, CA). Growth rates of treated and untreated mycelium were compared by least significant difference pairwise comparison.

\section{RESULTS}

Mycelial growth of M. fructicola isolates DL25W, DL13W, and SY3 was completely inhibited by hygromycin B at $30 \mu \mathrm{g} / \mathrm{ml}$ (data not shown). However, approximately one hygromycin B-resistant mutant was recovered per $2.5 \times 10^{5}$ germinating conidia from each isolate on selection medium containing hygromycin B at $50 \mu \mathrm{g} / \mathrm{ml}$ (data not shown). Hygromycin B-resistant colonies developed from germinating DL25W conidia in each of six additional experiments (Table 1). Between 28.2 and $50.0 \%$ of the colonies maintained hygromycin B resistance after transfer of mycelial plugs to fresh selection medium. Three hygromycin B-resistant colonies (4-26, 5-18, and 5-26) designated as DL25 mutants were selected at random to study the stability and effectiveness of the hygromycin B resistance. Hygromycin B resistance was maintained after five consecutive transfers on PDA, indicating that the acquired resistance was stable on nonselective medium. The mechanism of resistance was very effective, allowing the DL25 mutants to grow on PDA plates amended with hygromycin B at up to $300 \mu \mathrm{g} / \mathrm{ml}$ with no inhibition of mycelium growth (data not shown). Due to abnormal morphology, mutants were identified as bonafide $M$. fructicola by restriction fragment length polymorphism and sequence analysis. Amplified ribosomal ITS1 regions from mutants, transformants, and wild-type strains were identical in size (250 bp; Fig. 1A) and $M s e I$ restriction pattern (Fig. 1B). Identical ribosomal ITS1 and ITS2 nucleotide sequences from DL25W, the DL25 mutants, and DL25H also confirmed that the DL25 mutants and DL25H derived from DL25W (data not shown).

In order to compare the spontaneously developing hygromycin B resistance with resistance based on the $h p h$ gene, we transformed M. fructicola using Agrobacterium tumefaciens-mediated transformation with vector $\mathrm{pBHt} 1$ and conidia of $M$. fructicola

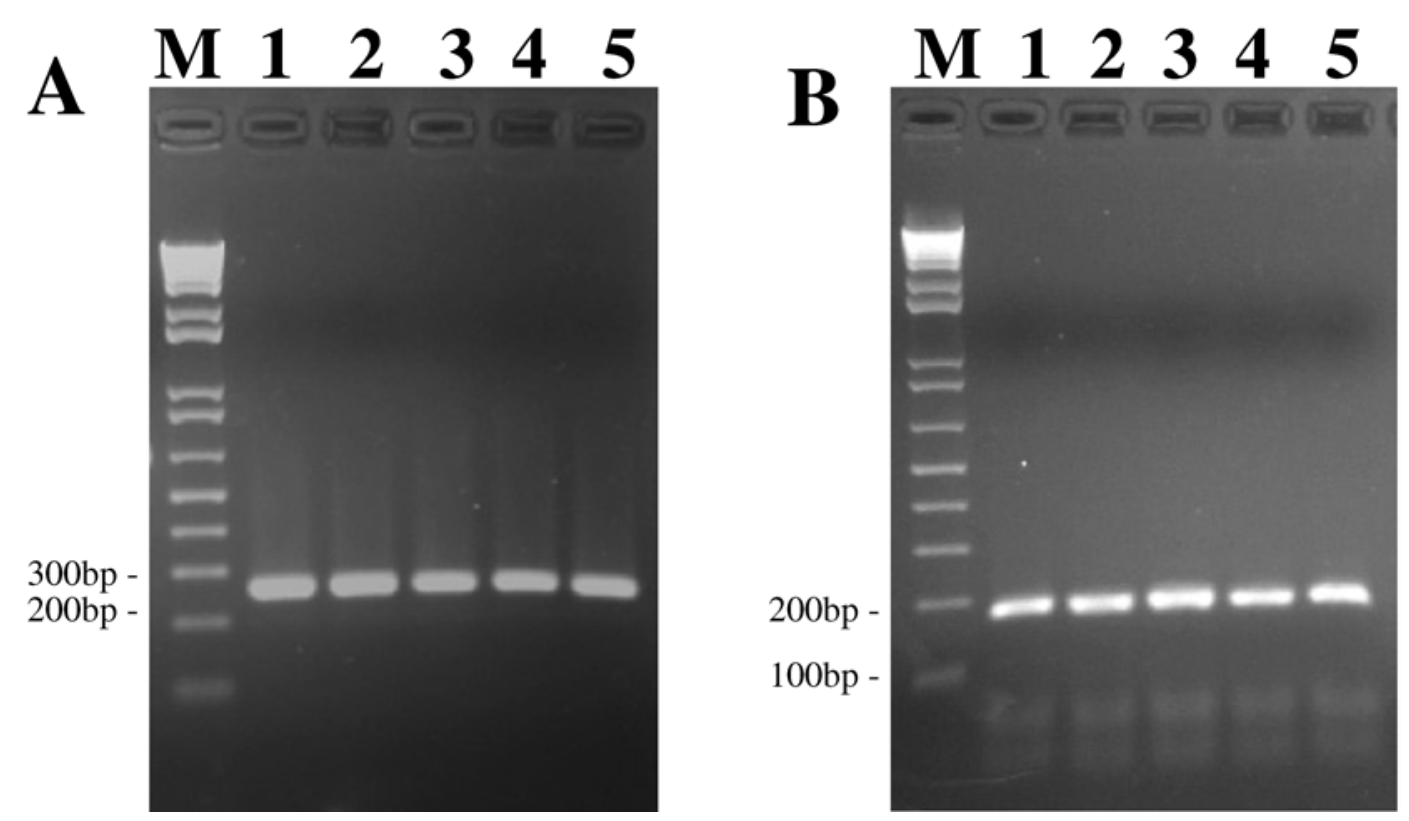

Fig. 1. Polymerase chain reaction and restriction analysis of the ribosomal internal transcribed spacer (ITS)1 region from Monilinia fructicola DL25W, DL25H, and DL25 mutants. A, DNA fragments were amplified with primers ITS1-F and ITS2 and B, subsequently digested with MseI. Lane M, 1-kb Plus DNA ladder; lane 1, DL25 mutant 4-26; lane 2, DL25 mutant 5-18; lane 3, DL25 mutant 5-26; lane 4, DL25W; and lane 5, DL25H.

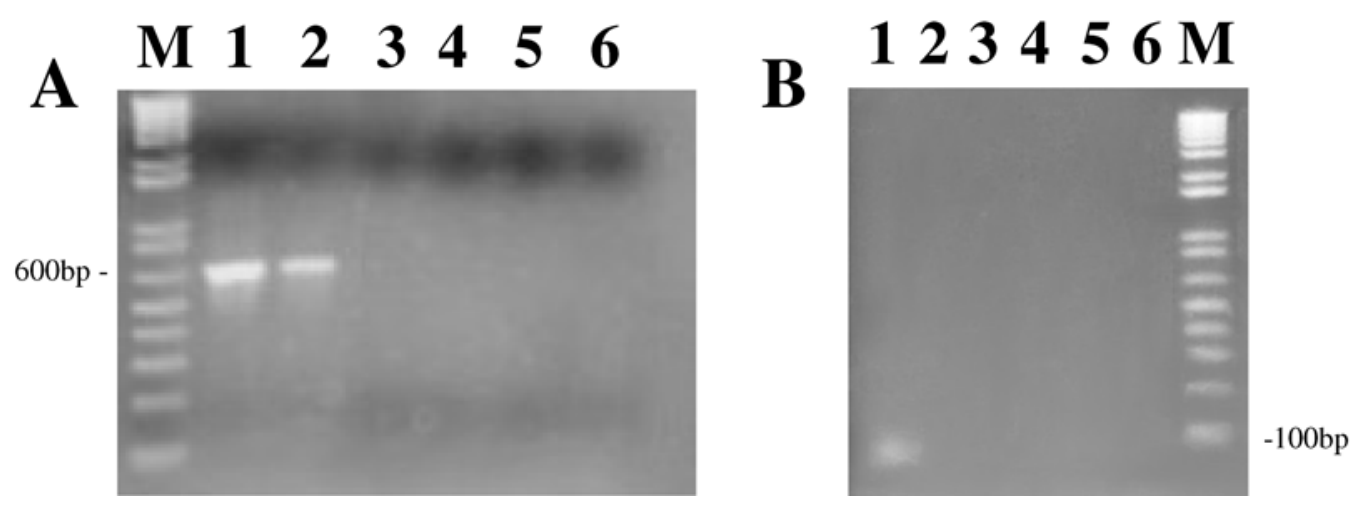

Fig. 2. A, Polymerase chain reaction (PCR) amplification of genomic DNA from Monilinia fructicola DL25W, DL25H, and the DL25 mutants with primers hph-F and hph-R. Lane M, 1-kb Plus DNA ladder; lane 1, Plasmid DNA (pBHt1); lane 2, DL25H; lane 3, DL25 mutant 5-26; lane 4, DL25 mutant 4-26; lane 5, DL25 mutant 518; lane 6, DL25W. B, PCR amplification of genomic DNA from M. fructicola DL25W, DL25H, and the DL25 mutants with Agrobacteriumspecific (25) primers. Lane 1, Agrobacterium DNA; lane 2, DL25H; lane 3, DL25 mutant 5-26; lane 4, DL25 mutant 4-26; lane 5, DL25 mutant 518; lane 6, DL25W; and lane M, 1-kb Plus DNA ladder. 
strain DL25W. One $h p h$ gene containing a hygromycin B-resistant colony was obtained per $1 \times 10^{8}$ conidia. The presence of the $h p h$ gene in transformant DL25H and the absence of the gene in DL25 mutants was verified by PCR (Fig. 2A). Also, the absence of Agrobacterium tumefaciens DNA in DNA isolated from DL25 mutants and DL25H was verified using Agrobacterium tumefaciens-specific primers (Fig. 2B).

Comparison of phenotypes of the DL25 mutants, DL25H, and the wild-type isolate DL25W revealed that the DL25 mutants grew significantly slower on PDA than DL25W and DL25H $(P=$ $0.05)$, but no difference was detected among the DL25 mutants (Fig. 3A). Interestingly, DL25H grew slightly faster than DL25W. Mycelial growth of DL25H was not inhibited on PDA amended with hygromycin B at $50 \mu \mathrm{g} / \mathrm{ml}$ (Fig. 3B). However, mycelium of DL25 mutants grew more slowly on this medium than DL25H $(P=0.05)$ (Fig. 3B). Again, there was no difference in mycelial growth rates among the DL25 mutants. Growth of DL25W was completely inhibited on hygromycin B-amended PDA. The DL25 mutants grew equally fast on peach halves but all grew more slowly $(P=0.05)$ than DL25W and DL25H (Fig. 3C). The DL25 mutants did not sporulate on peach halves; however, DL25H and DL25W produced spores abundantly after 4 days (Fig. 4). Similar results were observed after five consecutive transfers on PDA (data not shown). The sensitivity of the DL25 mutants, compared with DL25W, to DMI fungicides myclobutanil, propiconazole, and fenbuconazole was increased 2.3- to 3.1-fold (Table 2).

\section{DISCUSSION}

Genetic transformation of living cells is facilitated by selectable markers permitting growth of transformed colonies on media containing a selective agent. Hygromycin B resistance, conferred by the $h p h$ gene, is widely used for the identification and selection of transformants in a variety of cell types, including fungi $(7,8)$. Here we show that hygromycin B-resistant mutants of $M$. fructicola may develop spontaneously and consistently on hygromycin Bcontaining medium without transgene integration and that resistance is accompanied by significant changes in phenotype. This phenomenon may be widespread among $M$. fructicola populations in South Carolina and, possibly, elsewhere, based on the fact that spontaneous mutants developed from three isolates originating from two different locations in South Carolina.

Three hygromycin B-resistant M. fructicola mutants (DL25 mutants) were selected randomly to study the stability and effectiveness of hygromycin B resistance and the growth characteristics on hygromycin- or DMI fungicide-amended PDA and on peach halves. The DL25 mutants were positively identified as $M$. fructicola based on M. fructicola-specific MseI restriction patterns of the ITS1 region (24) and sequence analysis of the ribosomal ITS1 and ITS2 regions. The DL25 mutants grew more slowly on PDA and peach halves, did not sporulate, and had white mycelium, indicating that they lacked melanization. Reduced fitness and survival potential of nonmelanized $M$. fructicola conidia was observed recently (21). The authors suggested that melanin plays an important function in the life cycle of the pathogen. It may be that the reduced growth rate observed in DL25 mutants is based on the lack of melanization in the mycelium.

The DL25 mutants grew more slowly on hygromycin Bamended medium than DL25H, indicating that the mutant's resistance was less effective than transgenic resistance. Hygromycin B resistance in DL25 mutants was associated with reduced growth rates on multiple media, enhanced sensitivity to DMI fungicides, and lack of melanization and sporulation, indicating that significant pleiotropism was associated with this mutant form. All three DL25 mutants displayed equally altered phenotypes, suggesting similar resistance mechanisms. A sexual cross would need to be performed to conclusively state whether hygromycin B resistance in DL25 mutants is controlled by a single locus or multiple loci.
Hygromycin B inhibits protein synthesis at the translocation step of the $70 \mathrm{~S}$ ribosome and induces misreading of mRNA templates $(5,9)$. Resistance to hygromycin B has been reported in chemically induced, laboratory mutants of Aspergillus nidulans (16) and Saccharomyces cerevisiae (19). Hygromycin B resistance also was reported in progeny of a cross of two hygromycin Bsensitive Aspergillus nidulans mutants, a phenomenon thought to result from complementary gene action (17). Interestingly, the resistance segregated with slower growth and poor conidiation, characteristics that also were observed in M. fructicola mutants in this study. Hygromycin B resistance in Candida albicans developed after knock out of the CGT1 gene (6). The C. albicans mutants exhibited wrinkled colonies, a phenotype associated with branched hyphal cells producing very few blastospores (20). In our study, the development of resistance to hygromycin B was not a result of chemical or genetic transformation. No information is available to date on the mode of action of the inherent hygromycin $\mathrm{B}$ resistance of some fungi. Spontaneously developing, hygromycin B-resistant mutants were described only for Aspergillus

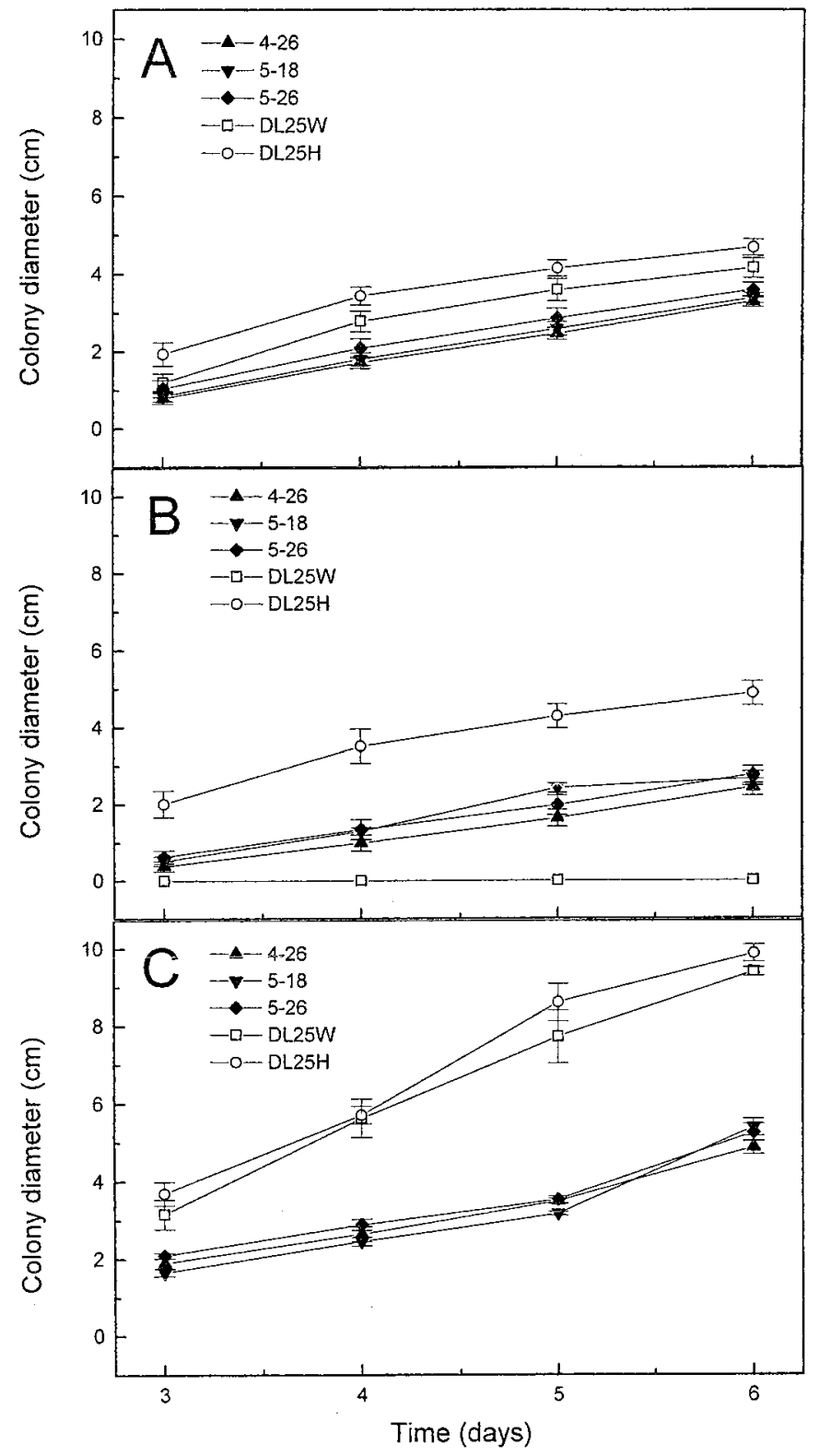

Fig. 3. Growth of Monilinia fructicola DL25W, DL25H, and the DL25 mutants (4-26, 5-18, and 5-26) A, on potato dextrose agar (PDA), B, PDA amended with hygromycin B at $50 \mu \mathrm{g} / \mathrm{ml}$, and $\mathbf{C}$, canned peach halves. Average of six replicates. Error bars denote the standard deviation for each mean. 


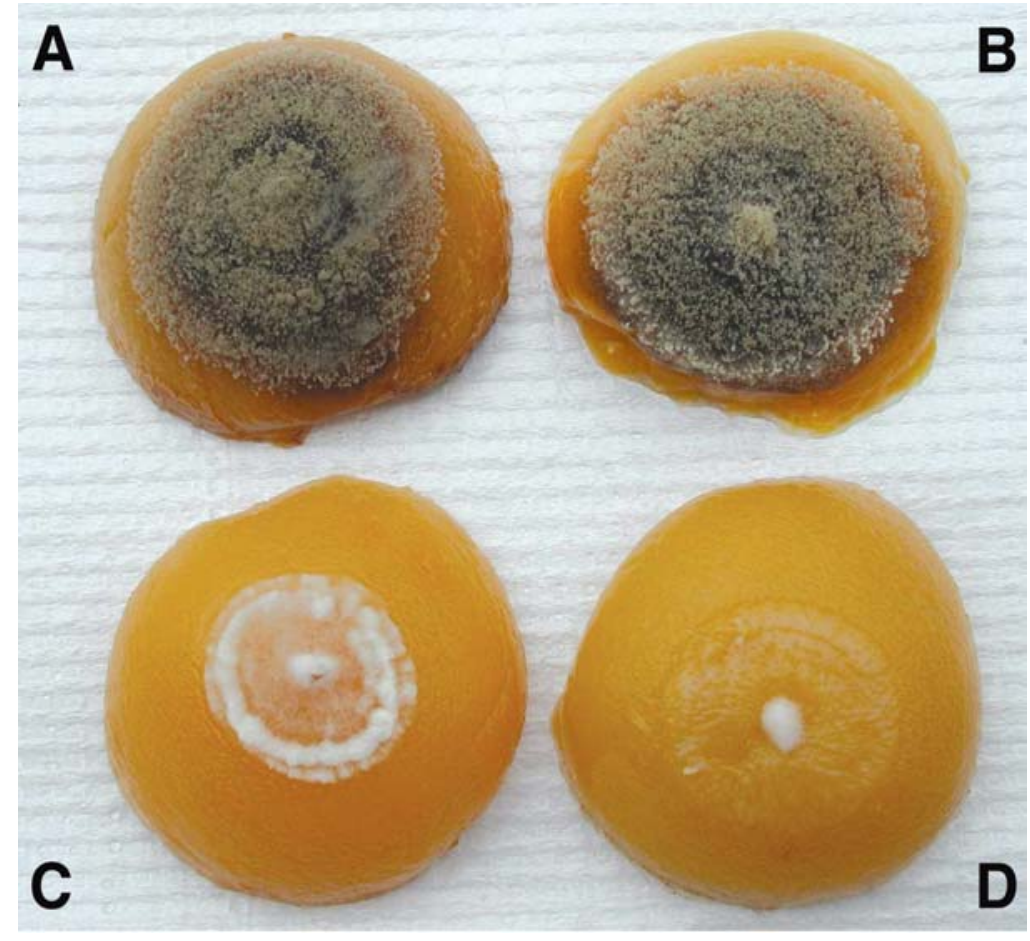

Fig. 4. Development of Monilinia fructicola DL25W, DL25H, and two of the DL25 mutants on canned peach halves after 4 days of incubation: A, DL25H, B, DL25W, C, DL25 mutant 4-26, and D, DL25 mutant 5-18.

TABLE 2. Sensitivity of Monilinia fructicola isolates DL25W, DL25H, and the DL25 mutants (4-26, 5-18, and 5-26) to demethylation inhibitor (DMI) fungicides myclobutanil, propiconazole, and fenbuconazole

\begin{tabular}{|c|c|c|c|c|c|c|}
\hline \multirow[b]{3}{*}{ Strain } & \multicolumn{6}{|c|}{ DMI fungicides } \\
\hline & \multicolumn{2}{|c|}{ Myclobutanil } & \multicolumn{2}{|c|}{ Propiconazole } & \multicolumn{2}{|c|}{ Fenbuconazole } \\
\hline & $\mathrm{EC}_{50}^{\mathrm{y}}$ & $\mathrm{SF}^{\mathrm{z}}$ & $\mathrm{EC}_{50} \mathrm{y}^{\mathrm{y}}$ & $\mathrm{SF}^{\mathrm{z}}$ & $\mathrm{EC}_{50} \mathrm{y}^{\mathrm{y}}$ & $\mathrm{SF}^{\mathrm{z}}$ \\
\hline $4-26$ & $0.31 \mathrm{a}$ & 2.3 & $0.009 \mathrm{a}$ & 3.5 & $0.007 \mathrm{a}$ & 2.6 \\
\hline $5-18$ & $0.28 \mathrm{a}$ & 2.5 & $0.011 \mathrm{a}$ & 2.8 & $0.007 \mathrm{a}$ & 2.7 \\
\hline $5-26$ & $0.30 \mathrm{a}$ & 2.4 & $0.010 \mathrm{a}$ & 3.1 & $0.008 \mathrm{a}$ & 2.4 \\
\hline DL25H & $0.72 \mathrm{~b}$ & - & $0.021 \mathrm{~b}$ & - & - & - \\
\hline DL25W & $0.71 \mathrm{~b}$ & - & $0.030 \mathrm{~b}$ & - & $0.020 \mathrm{~b}$ & - \\
\hline
\end{tabular}

${ }^{\mathrm{y}} \mathrm{EC}_{50}$ values were calculated by regressing the relative growth (colony diameter on DMI-amended medium divided by the diameter on unamended medium multiplied by 100) against the log of the fungicide concentration. Means within the same column followed by the same letter do not differ significantly $(P<0.05)$.

${ }^{z}$ The sensitivity factor (SF) indicates how much more the isolate was susceptible to a DMI fungicide than wild-type isolate DL25W. - Indicates that the data were not determined.

nidulans prior to this study and occurred at a lower frequency of one mutant per $6 \times 10^{8}$ conidia (16). No altered phenotype was reported to be associated with these mutants. However, in the same study, spontaneously developing paromomycin-resistant mutants were shown to grow more slowly and be more sensitive to lower temperatures (16).

Although spontaneous development of fungicide resistance usually is a result of somatic point mutations, it appears unlikely that the same point mutation would suddenly develop in a number of different cells at the same time. M. fructicola possesses multinucleate cells; therefore, hygromycin B resistance may be maintained in nuclei that occur in certain ratios with wild-type nuclei, which suppress the mutant pleiotropic growth described. Hygromycin B-resistant nuclei may have been selected for germinating conidia, but not in older mycelium. The resistant nuclei may have been defective in other cell functions, resulting in reduced growth rate, enhanced DMI fungicide sensitivity, and loss of melanization and sporulation.
The ability of $M$. fructicola and possibly other fungi to spontaneously develop hygromycin B resistance associated with an altered phenotype, reported here for the first time, may interfere with the selection of true transformants if hygromycin B is used as the selective agent. This is particularly confounding if the $h p h$ gene is used as a selectable marker in insertional mutagenesis experiments conducted for the identification of genes involved in melanization, sporulation, or fungicide resistance. Investigation of the molecular or physiological basis of the altered phenotypes in nontransformed hygromycin B-resistant mutants also may provide valuable insights in the pathways critical for sporulation or fungicide resistance.

\section{ACKNOWLEDGMENTS}

We thank S. Kang for supplying pBHt1 in Agrobacterium tumefaciens strain AGL-1 and K. Bryson for excellent technical assistance.

\section{LITERATURE CITED}

1. Batra, L. R. 1991. World species of Monilinia (fungi): Their ecology, biosystematics and control. Mycol. Mem. 16:110-116.

2. Biggs, A. R., and Northover, J. 1985. Inoculum sources for Monilinia fructicola in Ontario peach orchards. Can. J. Plant Pathol. 7:302-307.

3. Bundock, P., den Dulk-Ras, A., Beijersbergen, A., and Hooykaas, P. J. J. 1995. Trans-kingdom T-DNA transfer from Agrobacterium tumefaciens to Saccharomyces cerevisiae. Eur. Mol. Biol. Organ. 14:3206-3214.

4. Chung, K. R., Shilts, T., Li, W., and Timmer, L. W. 2002. Engineering a genetic transformation system for Colletotrichum acutatum, the causal fungus of lime anthracnose and postbloom fruit drop in citrus. FEMS Microbiol. Lett. 213:33-39.

5. Dean, N. 1995. Yeast glycosylation mutants are sensitive to aminoglycosides. Proc. Natl. Acad. Sci. USA 92:1287-1291.

6. De Backer, M. D., Hoogt, R. A., Froyen, G., Odds, F. C., Simons, F., Contreras, R., and Luyten, W. H. M. L. 2000. Single allele knock-out of Candida albicans CGT1 leads to unexpected resistance to hygromycin B and elevated temperature. Microbiology 146:353-365.

7. De Groot, M. J. A., Bundock, P., Hooykaas, P. J. J., and Beijersbergen, A. G. M. 1998. Agrobacterium tumefaciens-mediated transformation of filamentous fungi. Nature Biotechnol. 16:839-842.

8. Gao, S., Choi, G. H., Shain, L., and Nuss, D. L. 1996. Cloning and targeted disruption of enpg-1, encoding the major in vitro extracellular 
endopolygalacturonase of the chestnut blight fungus, Cryphonectria parasitica. Appl. Environ. Microbiol. 62:1984-1990.

9. Gonzales, A., Jimenez, A., Vazquez, D., Davies, J. E., and Schindler, D. 1978. Studies on the mode of action of hygromycin B, an inhibitor of translocation in eukaryotes. Biochim. Biophys. Acta 521: 459.

10. Hall, R. 1963. Cytology of the asexual stages of the Australian brown rot fungus Monilinia fructicola (Wint.) Honey. Cytologia 28:181-193.

11. Heuberger, J. W. 1934. Fruit rotting Sclerotinias IV. A cytological study of Sclerotinia fructicola (Wint.) Rehm. Univ. Md. Agric. Exp. Stn. Bull. 371:167-189.

12. Hoffman, G. M. 1972. Heterokaryose bei Wildstaemmen von Monilinia fructigena. Phytopathol. Z. 73:326-340.

13. Jerome, S. M. R. 1958. Brown rot of stone fruits: Latent contamination in relation to spread of the disease. J. Aust. Inst. Agric. Sci. 24:132-140.

14. Landgraf, F. A., and Zehr, E. 1982. Inoculum sources for Monilinia fructicola in South Carolina peach orchards. Phytopathology 72:185190.

15. Maheshwari, R. 1991. A new genotype of Neurospora crassa that selectively produces abundant microconidia in submerged shake culture. Exp. Mycol. 15:346.

16. Martinelli, S. D., and Sheikh, A. 1991. Hygromycin- and paromomycinresistant mutants of Aspergillus nidulans alter translational fidelity. Curr. Genet. 20:211-218.

17. Martinelli, S. D., and Zamir, A. 1987. Variable susceptibility of laboratory strains of Aspergillus nidulans to hygromycin B and other ribosomal antibiotics. Fungal Genet. Newsl. 34.

18. Mullins, E. D., Chen, X., Romaine, P., Raina, R., Geiser, D. M., and Kan, S. 2001. Agrobacterium-mediated transformation of Fusarium oxysporum: An efficient tool for insertional mutagenesis and gene transfer. Phytopathology 91:173-180.
19. Perlin, D. S., Brown, C. L., and Haber, J. E. 1988. Membrane potential defect in hygromycin B-resistant pmal mutants of Saccharomyces cerevisiae. J. Biol. Chem. 263:18118-18122.

20. Radford, D. L., Challacombe, S. J., and Walter, J. D. 1994. A scanning electron microscopy investigation of the structure of colonies of different morphologies produced by phenotypic switching of Candida albicans. J. Med. Microbiol. 40:416-423.

21. Rehnstrom, A. L., and Free, S. J. 1996. The isolation and characterization of melanin-deficient mutants of Monilinia fructicola. Physiol. Mol. Plant Pathol. 49:321-330.

22. Selker, E. U., Cambareri, E. B., Jensen, B. C., and Haack, K. R. 1987. Rearrangement of duplicated DNA in specialized cells of Neurospora. Cell 51:741-752.

23. Smilanick, J. L., Denis-Arrue, R., Bosch, J. R., Gonzalez, A. R., Henson, D., and Janisiewicz, W. J. 1993. Control of postharvest brown rot of nectarines and peaches by Pseudomonas species. Crop Prot. 12:513-520.

24. Snyder, C. L., and Jones, A. L. 1999. Genetic variation between strains of Monilinia fructicola and Monilinia laxa isolated from cherries in Michigan. Can. J. Plant Pathol. 21:70-77.

25. Weller, S. A., Simpkins, S. A., Stead, D. E., Kurdziel, A., Hird, H., and Weekes, R. J. 2002. Identification of Agrobacterium spp. present within Brassica napus seed by TaqMan PCR-implicatios for GM screening procedures. Arch. Microbiol. 178:338-343.

26. White, T. J., Bruns, T., Lee, S., and Taylor, J. 1990. Amplification and direct sequencing of fungal ribosomal RNA genes for phylogenetics. In: PCR Protocols: A Guide to Methods and Applications. Academic Press, San Diego, CA.

27. Willetts, H. J., and Calonge, F. D. 1969. Spore development in the brown rot fungi (Sclerotinia spp.). New Phytol. 68:123-131.

28. Zehr, E., Luszcz, L. A., Olien, W. C., Newall, W. C., and Toler, J. E. 1999. Reduced sensitivity in Monilinia fructicola to propiconazole following prolonged exposure in peach orchards. Plant Dis. 83:913-916. 